\title{
Video Article \\ Training Persons with Spinal Cord Injury to Ambulate Using a Powered Exoskeleton
}

\author{
Pierre K. Asselin ${ }^{1}$, Manuel Avedissian ${ }^{1}$, Steven Knezevic ${ }^{1}$, Stephen Kornfeld ${ }^{2}$, Ann M. Spungen ${ }^{1}$ \\ ${ }^{1}$ Department of Veterans Affairs (VA) Rehabilitation Research and Development National Center of Excellence for the Medical Consequences of Spinal Cord Injury, \\ James J. Peters VA Medical Center \\ ${ }^{2}$ Department of Veterans Affairs (VA) Spinal Cord Injury Service, James J. Peters VA Medical Center
}

Correspondence to: Ann M. Spungen at Ann.Spungen@va.gov

URL: https://www.jove.com/video/54071

DOI: doi:10.3791/54071

Keywords: Bioengineering, Issue 112, 6MWT, ambulatory device, overground walking, paraplegia, powered exoskeleton, reciprocating gait orthosis, RGO, and spinal cord injury

Date Published: 6/16/2016

Citation: Asselin, P.K., Avedissian, M., Knezevic, S., Kornfeld, S., Spungen, A.M. Training Persons with Spinal Cord Injury to Ambulate Using a Powered Exoskeleton. J. Vis. Exp. (112), e54071, doi:10.3791/54071 (2016).

\section{Abstract}

Powered exoskeletons have become available for overground ambulation in persons with paralyses due to spinal cord injury (SCI) who have intact upper extremity function and are able to maintain upright balance using forearm crutches. To ambulate in an exoskeleton, the user must acquire the ability to maintain balance while standing, sitting and appropriate weight shifting with each step. This can be a challenging task for those with deficits in sensation and proprioception in their lower extremities. This manuscript describes screening criteria and a training program developed at the James J. Peters VA Medical Center, Bronx, NY to teach users the skills needed to utilize these devices in institutional, home or community environments. Before training can begin, potential users are screened for appropriate range of motion of the hip, knee and ankle joints. Persons with $\mathrm{SCl}$ are at an increased risk of sustaining lower extremity fractures, even with minimal strain or trauma, therefore a bone mineral density assessment is performed to reduce the risk of fracture. Also, as part of screening, a physical examination is performed in order to identify additional health-related contraindications.

Once the person has successfully passed all screening requirements, they are cleared to begin the training program. The device is properly adjusted to fit the user. A series of static and dynamic balance tasks are taught and performed by the user before learning to walk. The person is taught to ambulate in various environments ranging from indoor level surfaces to outdoors over uneven or changing surfaces. Once skilled enough to be a candidate for home use with the exoskeleton, the user is then required to designate a companion-walker who will train alongside them. Together, the pair must demonstrate the ability to perform various advanced tasks in order to be permitted to use the exoskeleton in their home/community environment.

\section{Video Link}

The video component of this article can be found at https://www.jove.com/video/54071/

\section{Introduction}

Many persons with spinal cord injury $(\mathrm{SCl})$ are unable to stand and ambulate with or without the use of an assistive device or physical assistance. For centuries, the only mobility option for those with severe $\mathrm{SCI}$ has been the wheelchair ${ }^{1}$. During the past few decades, persons with $\mathrm{SCI}$ have had the option to supplement their mobility by using passive orthotic devices such as a variety of reciprocating gait orthosis $(R G O)^{2-7}$. These devices, however, have not become more widely used due to the physical effort required by the user to ambulate using these devices. The RGOs also have limitations in the ability to climb stairs, stand up, and sit down ${ }^{3,7}$. Efforts have been made to enhance the efficiency of these devices by incorporating Functional Electrical Stimulation (FES) to power the movement and help facilitate the forward swinging of the limb; however, these efforts have not progressed beyond concepts or prototypes ${ }^{8-12}$. In the 1970 s, motors were incorporated with an orthosis to power the movement of the hip and knee joints and was successful in allowing a person with $\mathrm{SCl}$ to take steps ${ }^{13}$. However, inadequate battery and computer technology of the time limited the range of the device, and further development was abandoned ${ }^{10,13}$.

With recent technological advancements, several powered exoskeletons have been developed to enable persons with various pathologies to ambulate overground. These powered exoskeleton devices have been studied in persons with stroke ${ }^{14,15}$, persons with complete and incomplete $\mathrm{SCl}^{16-24}$, and other persons with disabilities causing reduced control of their lower extremities ${ }^{25-27}$. Although the devices differ, each one requires training and practice by the user for safe performance. Three of the referenced devices require the use of crutches to ambulate and maintain balance. The fourth one maintains balance and stability because of its large footplate and mass which enlarges the base of support and lowers the center of gravity ${ }^{20}$. The three devices that require crutching utilize the same principles even though there are some variations with the mechanics and methods of controlling the desired actions due to differences in the design of the devices.

A training program was developed at the James J. Peters VA Medical Center (JJPVAMC), Bronx, NY by a group of researchers consisting of a biomedical engineer, physiologist, physiatrist, exercise physiologist, neurologist and physical therapists. The training program was 
developed with one specific powered exoskeleton previously described ${ }^{17,18}$ but it incorporates sets of skills that are applicable to other powered exoskeletons which require a set of crutches to maintain balance. All potential participants were screened prior to participating in the progressive training program. The importance of screening in persons with $\mathrm{SCl}$ is to ensure absence of contraindicated medical complications that may inhibit the safe use of these devices. One area of concern is low bone mineral density (BMD). Persons with SCl suffer dramatic bone loss immediately after injury ${ }^{28,29}$ which may continue throughout their lives ${ }^{30}$. This loss of BMD results in a high risk of long bone fractures. Currently, there is no effective treatment to mitigate bone loss for those with complete motor SCl. In addition, an established fracture threshold for person with SCI does not exist, but efforts have been made to identify criteria which may be used as a guide ${ }^{31-33}$ along with clinical judgement and fracture history. Other common contraindications may be treated and resolved, such as limited range of motion (ROM) ${ }^{34}$ and pressure ulcers ${ }^{35}$. Each of the different powered exoskeleton may require different conditions for eligibility, such as ROM criteria, to be a candidate to use the device, most of which have been described ${ }^{17-19,21,22,36}$.

Once a person has successfully passed all of the screening criteria, fitting the device to the user and training may proceed. Proper fitting of the device is important to avoid inappropriate contact of the lower extremities with the exoskeleton because poor fitting may lead to bruising and/ or skin abrasions ${ }^{16}$. Users may have limited or no lower extremity sensation and proprioception; this lack of sensory and tactile feedback from the feet can contribute to an overall lack of awareness of their center of balance, slowing the user's ability to master the device. This lack of awareness of the center of balance may also lead to challenges with appropriate weight shifting such as difficulty in gauging the extent of the forward and lateral shift necessary during the gait cycle and inappropriately timed weight shifting, resulting in excess use of weight bearing on the arms and crutches for balance maintenance. Once the basics mechanisms of standing balance and weight shifting are acquired, the user is taught to walk in the device. Multiple sessions are needed to improve walking and other mobility skills. Initially, surfaces that are flat and smooth within the medical center are used for training. However, with improved skill level, the user is challenged with incrementally more difficult tasks by introducing different walking surfaces such as carpet, asphalt, concrete, grass, and unleveled surfaces with different degrees of slopes.

The purpose of this manuscript is to report the screening criteria, proper fitting and training procedures for use a powered exoskeleton for overground walking. This program was developed for one device specifically, which is described by others ${ }^{16-18}$, but it addresses aspects and challenges that are common for staff trainers and persons with $\mathrm{SCl}$ who participate in exoskeletal-assisted walking programs which may use another powered exoskeleton. Certain aspects of this protocol are specific to the device used at the JJPVAMC. Additionally, some of the components of the training program were developed by the manufacture which includes orientation of the device components, basic guidelines for a proper fit and basic standing and sitting skill instructions. The researchers at the JJPVAMC developed all training activities performed once the user is standing up. These include enhancement of the standing and sitting training instructions, standing balance skills, indoor walking progression skills, outdoor walking progression skills, and other mobility tasks for reaching, stopping, turning, and various types of door/threshold navigation.

\section{Protocol}

Note: The training protocol described within this manuscript was developed during a pilot project entitled: "The ReWalk Exoskeletal Walking System for Persons with Paraplegia" registered with ClinicalTrials.gov identifier NCT01454570. Developing a training program was not the objective of this pilot project however; the training program evolved during the course of conducting this study. The study protocol and informed consent form were reviewed and approved by the JJPVAMC's Institutional Review Board (IRB). The entire study and the procedures were explained to each study participant. The potential participant was given the opportunity to ask questions and was encouraged to take as much time as needed prior to consenting.

\section{Participant Recruitment}

1. Perform a pre-screening evaluation with the potential participants.

1. Briefly explain the details of the training process (length of study, times per week, hours per day). Explain the known risks of participation (skin abrasions, potential injury if one were to fall and the potential for unforeseeable events).

Note: Within this protocol the training sessions occurred 3 times per week and lasted between 60 to 90 min. A specific frequency and/ or duration of the training sessions are not required in order for the participants to learn to use the powered exoskeleton.

1. Describe the medical restrictions to the potential participant such as: low bone mineral density at the hip or knee, recent history of fractures, unable to tolerate standing, weak upper extremity strength and, weak trunk control. Review the inclusion and exclusion criteria in order to continue to the screening process. Encourage the potential participant to ask questions. Provide ample time to address any concerns and answer questions.

Note: The anthropometric restrictions for the specific powered exoskeleton used herein were applied to the inclusion criteria for: height $<160$ or $>190 \mathrm{~cm}$ and weight $<100 \mathrm{~kg}$.

2. If the prescreening evaluation is successful, then provide a detailed explanation of the study and initiate the screening process.

1. Perform a dual energy $x$-ray absorptiometry (DXA) scan to evaluate bone mineral density bilaterally at the hip and knee.

Note: The facility has limited the use of the exoskeletons to persons who have a T-Score at the total hip and femoral neck to be greater than -3.5 and $a$ BMD at the proximal tibia and distal femur to be greater than $0.60 \mathrm{~g} / \mathrm{cm}^{2}$. These values do not eliminate the risk of fracture but were chosen in an effort to reduce the risk. Clinicians are encouraged to review the relevant literature and adjust the values according to their interpretation of the information ${ }^{31-33}$.

2. Perform the International Standards for Neurological Classification of SCI (ISNSCI) ${ }^{37}$ examination to evaluate injury level, motor function and sensation.

Note: In this pilot research study participants with varying levels of injury were included and are presented in Table 1. Persons with paraplegia are the predominant users; however persons with cervical injuries who have upper extremity motor scores of 4 or better for the individual muscle groups and are able to maintain balance with the crutches may be a candidate for using this exoskeleton, as well as other powered exoskeletons. 
3. Obtain a general medical history and physical evaluation which also includes range of motion of the shoulders, hips and knees, and skin check of areas on the lower extremity and lower back that contacts the powered exoskeleton.

Note: Persons with limited hip and knee range of motion of $20^{\circ}$ of flexion or greater at either joints were excluded. Additionally, the shoulders must have had enough range of motion to achieve proper crutch placement to perform the sit-to-stand and stand-to-sit maneuvers. Participants must also be free of any pressure ulcers in the lower extremities, particularly any area with direct contact with the exoskeleton. These criteria may vary for each device and the clinicians should refer to the manufacturer for the requirements specific to that powered exoskeleton.

\section{Fitting}

Note: The fitting procedures were developed by the manufacture of the device. The methodology of fitting a person to the device will also vary among the different exoskeletons. Clinicians should refer to each of the specific manufacture's procedures.

1. Place the participant in a supine position. Using a flexible tape measure, determine the pelvic width, upper leg length and lower leg length and record in centimeters.

1. Measure the upper leg length from the most prominent point of the greater trochanter of the hip to the knee joint line. Measure the other limb in the same manner. Record any limb length discrepancies. Adjust the powered exoskeleton from the center of the hip axis to the center of the knee axis according to the distance measured on each of the participant's upper leg lengths.

2. Measure the lower leg length from the knee joint line to the bottom of the foot. Repeat the measurement for the other lower leg length. Adjust the length from the bottom of the footplate to the center of the knee axis on the powered exoskeleton for each lower limb according to the distances measured from the participant.

3. Adjust the width of the powered-exoskeleton using different size pelvic bands. Select the pelvic band by placing the participant in a seated position on a chair or bench with an open back. Place the pelvic band closest in size to the participant's pelvic width behind the person and slowly move it forward to test it for a fit. Allow up to $1 \mathrm{~cm}$ clearance on either side of the pelvic girdle.

Note: Other powered exoskeletons are adjusted in a different manner and appropriate adjustment should be obtained according to the manufacture's specifications.

4. After choosing the appropriate pelvic band size, affix the pelvic band to the thoracic uprights in the neutral or centered position. After the participate is in standing position, adjust the fore/aft position appropriately, if needed, so that the trochanter is in line with the rotation of the hip joint.

Note: The pelvic band can be set so that it can to push the hips anteriorly or posteriorly. The neutral or centered position is the setting of the pelvic band to that it allow for adjustments of equal amounts anteriorly or posteriorly.

2. Fit and adjust the foot plate by removing the participant's shoe, removing the insole from the shoe, then place the largest footplate possible into the shoe. Place the insole on top of the footplate. Adjust the dorsiflexion assistance of the footplate by fine-tuning the tension on the spring mechanism at the ankle.

3. After completing all measurements, the system is now ready for donning by the participant.

\section{Donning}

Note: The donning procedures were developed by the manufacture of the device. The methodology of donning a person to the powered exoskeleton may vary among the different devices and clinicians should refer to the manufacture's procedures.

1. Place the exoskeleton in a seated position on a chair with the strapping open.

Note: The ideal chair has a wide padded seat and must not have arm rests or wheels.

1. Instruct the participant to place their wheelchair next to the seated exoskeleton at a slight angle.

2. Ask the participant to transfer into the device by placing one hand on the device, the other on their wheelchair. Ensure that the participant performs the transfer into the device in one continuous motion. If the participant is unable to complete the transfer in one movement, encourage them to rest momentarily on the upper "thigh" portion of the exoskeleton, and to resume the transfer with a second motion.

Note: Assistance with the transfer may be provided if needed.

2. After the participant is seated properly in the device, instruct the participant to first place their feet in the shoes, then continue securing the straps starting at the most distal point and moving proximally up the body, finishing with the chest straps.

1. If needed, use the manual control feature to flex the hip slightly and extend the knee to permit easier placement of the feet into the shoes.

2. Carefully guide the foot into the shoe, taking special care to ensure the toes are not curled. Once the foot is properly in the shoe, the use the manual controls to move the leg and foot back on the floor, then fasten the shoe. Follow the same steps to ensure proper placement of the second foot into the shoe.

3. After securing the feet in the shoes, secure the straps directly below the knees, followed by securing the straps above the knees and those for the upper thighs. Take care to avoid crumpling of clothing beneath the straps to avoid unwanted friction and/or pressure points of contact. Secure the lower and upper chest straps last.

3. Once the participant is strapped into the device, examine them for any inappropriate contact, crumpled clothing or pressure points.

1. Following identification of a pressure point, release the pressure by adjusting the fit and adding or removing padding as appropriate. Note: Examine the fit while seated, standing and after walking a few steps. The participant may shift slightly when standing and after walking which may lead to additional points of contact that may be identified by re-examination. 


\section{Standing}

Note: The procedure to stand-up was developed by the manufacture of the device and may vary among the different exoskeletons. Clinicians should refer to the manufacture's procedures.

1. After fitting, introduce the participant to the overall functions of the exoskeleton. Explain the controller specific to the device. Inform the participant that $\mathrm{s} / \mathrm{he}$ will be expected to become as independent as possible with the exoskeleton. Explain that independence will be accomplished by learning to control the functions of device and that there are short term and long term goals to become independent. Note: Initially the trainer operates the controls to initiate the desired movement of the powered exoskeleton, however it is important that the user be introduced to the device and made aware of how it functions as early as possible during the training process. Once comfortable in the device, the user takes over the controls and initiate their own movements.

2. Equip the participant with a set of forearm crutches to assist with balance and maneuverability of the device. While seated in the exoskeleton, instruct the participant to place the tips of the crutches posteriorly in a manner allowing them the ability to push their weight over their feet. This ensures that the exoskeleton can extend the hip and knee joints performing most of the work during the standing maneuver. Note: Crutches are needed for all maneuvers in the device including standing, walking, turning, and sitting. Participants are not permitted to use the exoskeleton without the crutches. Some powered exoskeletons may allow the use of a walker or a cane to maintain balance.

3. Explain the sit-to-stand procedure to the participant. Have one trainer assist from behind the user, and another guard from the front. Instruct the participant to stand on their own and only use trainer assistance as needed.

1. Instruct the participant to place the crutches posteriorly and lean forward while pushing off the crutches to assist the device in standing them after pressing the "Stand" command.

Note: Initially, encourage the user to concentrate on proper crutch placement while the trainer uses the controller to initiate the powered exoskeleton to standup.

\section{Standing Balance}

Note: The standing balance procedures were developed by the researchers at the JJPVAMC. There may be some procedures that are specific to the device used but most of the procedures should translate to other powered exoskeletons.

1. After standing with a trainer guarding from behind, have the second trainer stand in front of the user and demonstrate the standing balance goals.

Note: Measure blood pressure after standing and periodically during the training session to identify if an orthostatic hypotension or autonomic dysreflexia episode is experienced by the user.

2. Before attempting to walk, ensure that the participant demonstrates the following capabilities:

1. Have the participant demonstrate the ability to stand in "home" position using both crutches to maintain balance (Figure 1). Note: Place a mirror in front of the participant to provide visual feedback and help correct improper lean as well as maintain their upright balance in the "home" position.

2. Have the participant practice slight shifting of their weight laterally and posteriorly to understand the location and feel of the home position.

3. Instruct the participant to maintain balance with only one crutch (Figure 2). Instruct the participant to practice this action by lifting one crutch off of the ground and holding that stance for up to 1 minute. Instruct the participant to practice an additional one-handed balance exercise.

Note: This maneuver is similar to the previous one but with the added complexity of having one arm balancing while the contralateral arm reaches over to touch the balancing arm's wrist, simulating selection of actions on the controller.

1. Repeat these exercises to ensure the participant is able to perform these maneuvers using either arm to maintain balance.

4. After practicing the standing crutch balance skills, teach the participant to weight shift laterally, allowing one foot to offload, with the goal to lift the foot completely off the ground for $5 \mathrm{sec}$. Instruct the user to repeat this exercise, trying to offload with the other leg.

5. Ask the participant to weight shift in anterior and posterior directions while properly placing crutches fore and aft to maintain balance.

6. Repeat exercises 5.2.2 - 5.2.5 five to ten times during the first session. Continue to practice these exercises during the following sessions until the user feels comfortable with them.

\section{Walking}

Note: The walking procedures are a mixture of procedure developed by the staff at the JJPVAMC and the manufacture of the device. The mechanism of walking inbuilt into the powered exoskeleton and the dual crutch pattern used in the device was developed by the manufacture; however the approach of teaching the participant how to properly execute the walking, mechanism of providing assistance and the outcome measure used to record the level of assistance was the efforts of the researchers at the JPVAMC. Although, some procedures are specific to the powered exoskeleton used, most of the procedures are translatable to other powered exoskeletons that use crutches to maintain balance.

1. Instruct the participant in the mechanism of walking with the powered exoskeleton. The particular powered exoskeleton used requires the participant to shift their weight onto the left foot while simultaneously unweighting the right foot. Using the controller, the trainer selects the "Walk" mode and asks the participant to shift slightly forward (to a predetermined target); this will initiate forward swing of the right leg.

1. Instruct the user that once the right leg has completed the swing, to move their crutches forward while simultaneously shifting their weight forward and to the right in order to maintain balance while stepping onto the right foot, and unweighting the left foot. Explain that the device, sensing the participant's movement, will initiate forward swinging of the left leg.

2. Perform continuous walking by repeating the forward crutching motion and weight shifting sequence for each leg consecutively. 
2. Encourage the trainers to provide assistance as needed, however to do so minimally.

Note: The level of assistance, determined by the functional independence measure $(F I M)^{38}$, is assessed by the trainer and recorded.

1. Spot the user by grasping the powered exoskeleton or the participant to provide support if needed. Correct the user as s/he performs the proper weight shifting while walking.

2. If needed, have a second trainer provide assistance and tactical feedback in an area of the body which the user has intact sensation (such as the shoulders).

Note: Trainers are discouraged to provide assistance through the powered exoskeleton or below the level of injury because the user is not typically able to feel the assistance, which may lead to difficulty in learning to adjust their upper body to properly ambulate in the device.

3. Explain to the user the mechanism for the powered exoskeleton to stop walking. The particular powered exoskeleton used is triggered to stop when it does not sense any more forward movement onto the contralateral limb, or if the user does not provide an appropriate weight shift allowing the swing leg to make contact with the floor.

Note: Stopping at will or at a particular location is practiced and is one of the skills included in the training program.

\section{Progressive Goals of Mobility Training}

Note: The goals of the mobility training were developed at the JJPVAMC and incorporated within the criteria for evaluating proficiency to use the powered exoskeleton in the home environment by the manufacture.

1. Explain and describe the list of mobility skills to be practiced as part of the training (Figure 3).

1. Instruct the participant to use the controller of the powered exoskeleton and become as independent as possible using the powered exoskeleton.

Note: The powered exoskeleton used in this trial had the controls integrated in a controller worn on the wrist.

2. Teach the participant to make 90 and 180 degree turns while walking in the system.

3. Instruct the participant to navigate to rest on a wall by stopping beside the wall and turning so their back can lean against it. Note: This allows the person to rest without the need to rely on the crutches for balance.

4. Incorporate different walking surfaces during the training sessions so that the participant practices walking on additional surfaces such as carpet (Figure 4), concrete, asphalt, and grass (Figure 5).

5. Have the participant walk on surfaces with varying slopes such as up a ramp, down a ramp, curb cutout and uneven surfaces (Figure 6). Then, have the participant walk in a noisy environment, such as a hallway with other pedestrians.

Note: Walking in a noisy environment may be a challenge for some people since they are unable to hear the sound of the motors which provides an audio que for an appropriate time to weight shift.

6. Have the participant stop on command or at will.

7. Practice navigation of doorway thresholds, opening and closing of swinging doors, opening and closing doors from different sides, and walking through automatic and/or revolving doors (Figures 7 and 8 ).

Note: The ability of performing these additional mobility skills are assessed as "able" or "unable" to perform the maneuver.

8. Incorporate additional activities such as reaching over head into a cabinet (Figure 9) or outside sitting on and standing up from a park bench (Figure 10).

\section{Assessments of Walking}

Note: The walking assessments used are standard clinical tests that have been established by others.

1. Perform a 6 min walk test (6MWT).

1. Have the participant initiate walking and instruct the participant to continue walking.

2. After 6 min ask the participant to stop.

Note: The $6 \mathrm{MWT}^{39,40}$ is the distance that the participant is able to ambulate with the powered exoskeleton over a 6 min period of time. Should the participant accidentally trigger the device to stop walking during the 6MWT, the clock continues to record time and the participant is encouraged to regain his/her balance, composure, and re-start the device to continue walking as quickly as possible.

2. Perform this test with a trainer dedicated to spotting and an additional trainer using a measuring wheel to determine the distance and a stop watch to measure the elapsed time.

3. Express the $6 \mathrm{MWT}$ in meters walked in $6 \mathrm{~min}$ and calculate the average walking speed (total meters walked in $6 \mathrm{~min} / 360 \mathrm{sec}$ ) and express it as $\mathrm{m} / \mathrm{sec}$.

Note: The 6MWT is the total distance traveled during a 6-min timed period and is obtained over the course of the training program. The $6 \mathrm{MWT}$ is the primary assessment used to determine the progression of walking skill in the exoskeleton. Perform the 6MWT test as soon as the participant understands the mechanism of walking with the powered exoskeleton and is able to take multiple steps.

4. Use the lap function of the stopwatch during the 6MWT after covering a $10 \mathrm{~m}$ distance to record the $10 \mathrm{~m}$ time. Identify and record the best $10 \mathrm{~m}$ time achieved during the 6MWT.

Note: The 10 -meter walk test $(10 \mathrm{MWT})^{40}$ is the best effort time (seconds) it takes the participant to walk a $10 \mathrm{~m}$ distance, and is recorded while the person performs the 6MWT.

5. Use the timed-up-and-go (TUG) $)^{40,41}$ test as an indicator of how much standing, walking turning, and sitting function the individual has.

1. Perform the TUG test by measuring the time it takes the participant to stand up from a seated position, walk 10 feet, turn around, walk back and sit down again. Start the time once the person initiates the device to stand up and the time stops once the person is safely sitting in the seat. 
Note: The results of this measurement are not representative of the traditional TUG times because it incorporates the time allotted for proper crutch placement after the mode selector indicates standing is desired. The TUG measurement represents the person's ability to use the exoskeletal system since it incorporates multiple aspects of mobility in the device.

\section{Sitting}

Note: The procedures to sit down were developed by the manufacture of the device and may vary among the different exoskeletons. Clinicians should refer to the manufacture's procedures.

1. Place a chair behind the user when he or she is ready to sit. Using the controller of the exoskeleton, place the exoskeleton in sit mode. Note: Initially the trainer operates the controller during the sitting movement of the powered exoskeleton, however as with standing, it is important that the user be introduced to the controller and made aware of its functions as early as possible during the training program. Once comfortable in the device, the user is asked to operate the controller and initiate the movements.

2. After activating/pressing the sit command there is a 5-second delay. During this time ask the participant to place their crutches posteriorly to maintain their center of balance over the chair. Have the participant practice the crutch placement task if this is the first few times performing the sitting function. After the 5-second delay has elapsed, the exoskeleton lowers the user down until sitting on the chair.

3. During the sitting process the user will start to bend forward at the hip to maintain balance over the feet. Have the trainers assist the participant as needed.

Note: Initially, practice sitting with two trainers, one spotting from behind, and the other in front. As the user becomes skilled in the maneuver and able to complete the maneuver with confidence and independence, only one trainer is needed.

\section{Doffing}

Note: The doffing procedures were developed by the manufacture of the device. The methodology of doffing the powered exoskeleton may vary among the different devices. Clinicians should refer to the manufacture's procedures.

1. After seating, doff the device in a similar, but reverse manner as previously discussed in section three for donning the device.

1. Release the straps starting with the chest and hip and progress to the feet. Remove the participant's feet from the device. Encourage the participant to attempt the transfer into their wheelchair on their own, but provide assistance as needed.

2. Once back in their wheelchair, inspect the participant's feet, lower extremities, and lower back for any bruising or abrasions.

3. Teach the participant to routinely check their lower extremities for signs of pressure points after they have completed their walking sessions.

\section{Representative Results}

The following measurements are obtained throughout the training. Two handed and one handed crutch balance skills are each assessed for 1 min as "able" or "not able" to maintain balance (Figure 2). Walking assessments for time and distance are obtained throughout the training sessions using the 6MWT, 10MWT and the TUG. Exoskeletal-assisted walking on commonly encountered surfaces are tested indoors (Figures 3 and 4) and outdoors (Figures 5-6). Other mobility skills such as navigating doors (Figures 7 and 8), reaching over head into a cabinet (Figure 9) and sitting outside on a park bench (Figure 10) are assessed as "able" to perform or "not able" to perform.

Average walking speeds during the 10MWT in 10 session intervals for the first 60 sessions are depicted (Figure 11). This graph shows participants have varying initial ability to use the powered exoskeleton and varying rates of improvement among users. The average \pm standard deviation of the best fit line's slope is $0.0048 \pm 0.004 \mathrm{~m} / \mathrm{sec}$ and values ranged from 0.00026 to $0.015 \mathrm{~m} / \mathrm{sec}$. This indicates that although each participant improved at variable rates they walked an average of $0.0048 \mathrm{~m} / \mathrm{sec}$ faster each session. The average \pm standard deviation of the best fit intercept is $0.16 \pm 1.8 \mathrm{~m} / \mathrm{sec}$ and the values ranged from -0.026 to $0.50 \mathrm{~m} / \mathrm{sec}$. This indicates that on average participants have an average initial speed of $0.16 \mathrm{~m} / \mathrm{sec}$; with some participants having almost no ability to ambulate and others have a very good ability in the early stages of training.

Trainer assistance affects performance; those who need a greater level of assistance walk slower than those who are more proficient and independent in using the system ${ }^{18}$. The three walking test measurements, although similar, provide different proficiency information. The $10 \mathrm{MWT}$ provides an indication of the best effort for speed $(\mathrm{m} / \mathrm{sec})$ that the user is able to ambulate in the device. The 6MWT distance, when converted to speed in $\mathrm{m} / \mathrm{sec}$, provides an average walking speed and is an indication of the consistency of walking in the exoskeleton. Since the timer continues when the user accidently stops walking, the speed from a 6MWT that is closer to the best effort 10MWT indicates that the person had consistent walking and fewer stops. The TUG requires many skills to be performed in consecutive combination. The TUG is a measure of the person's overall ability to incorporate standing up, walking, turning, stopping, and sitting down in the powered exoskeleton. An overview of the 6MWT, 10MWT and the TUG measurements have been described previously by Yang $^{18}$ and are presented in Table 1 along with the patient demographic information of the participants. 


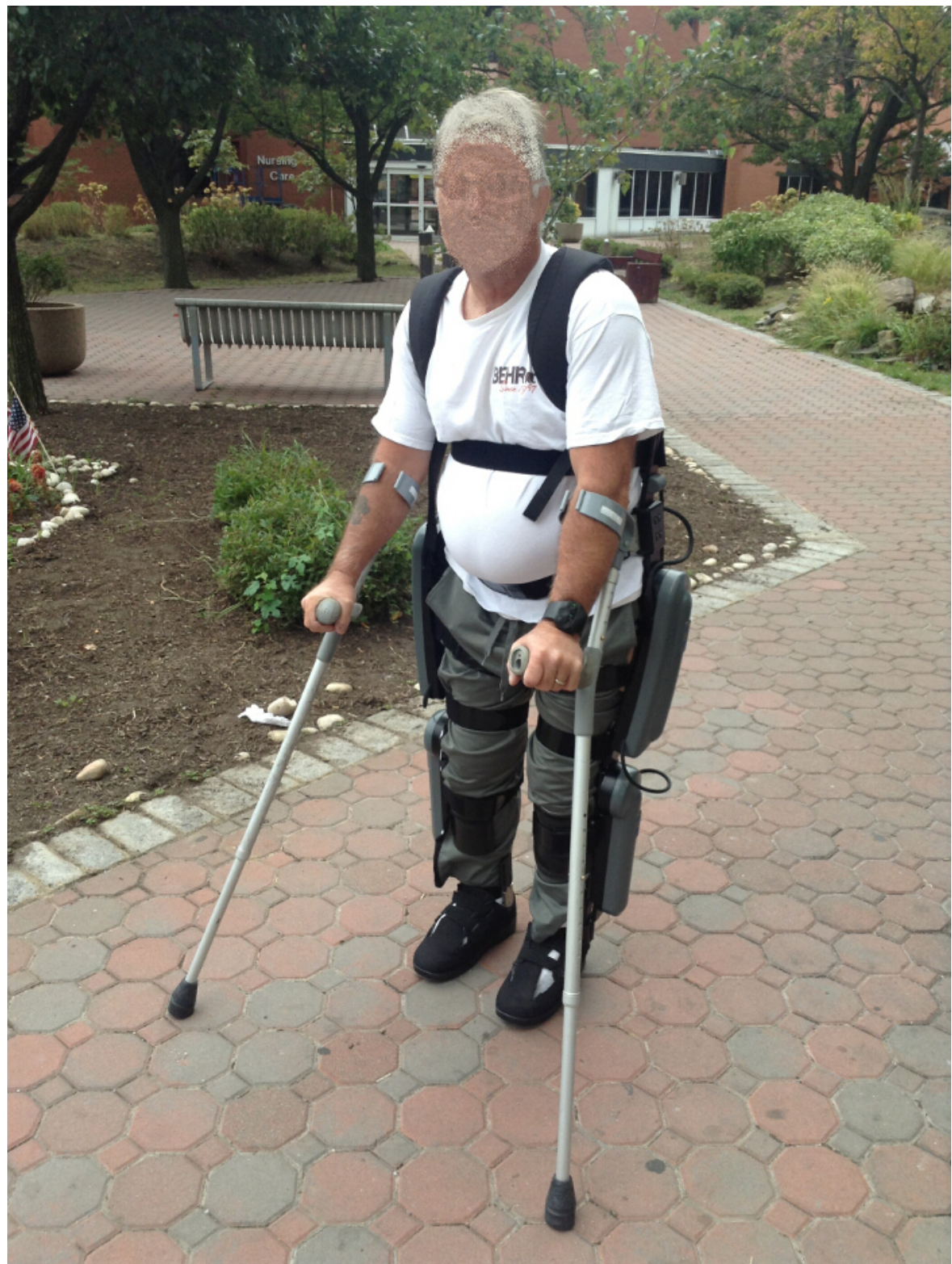

Figure 1. Two handed crutch balance. This figure demonstrates a person standing still and balancing with both crutches. Please click here to view a larger version of this figure. 


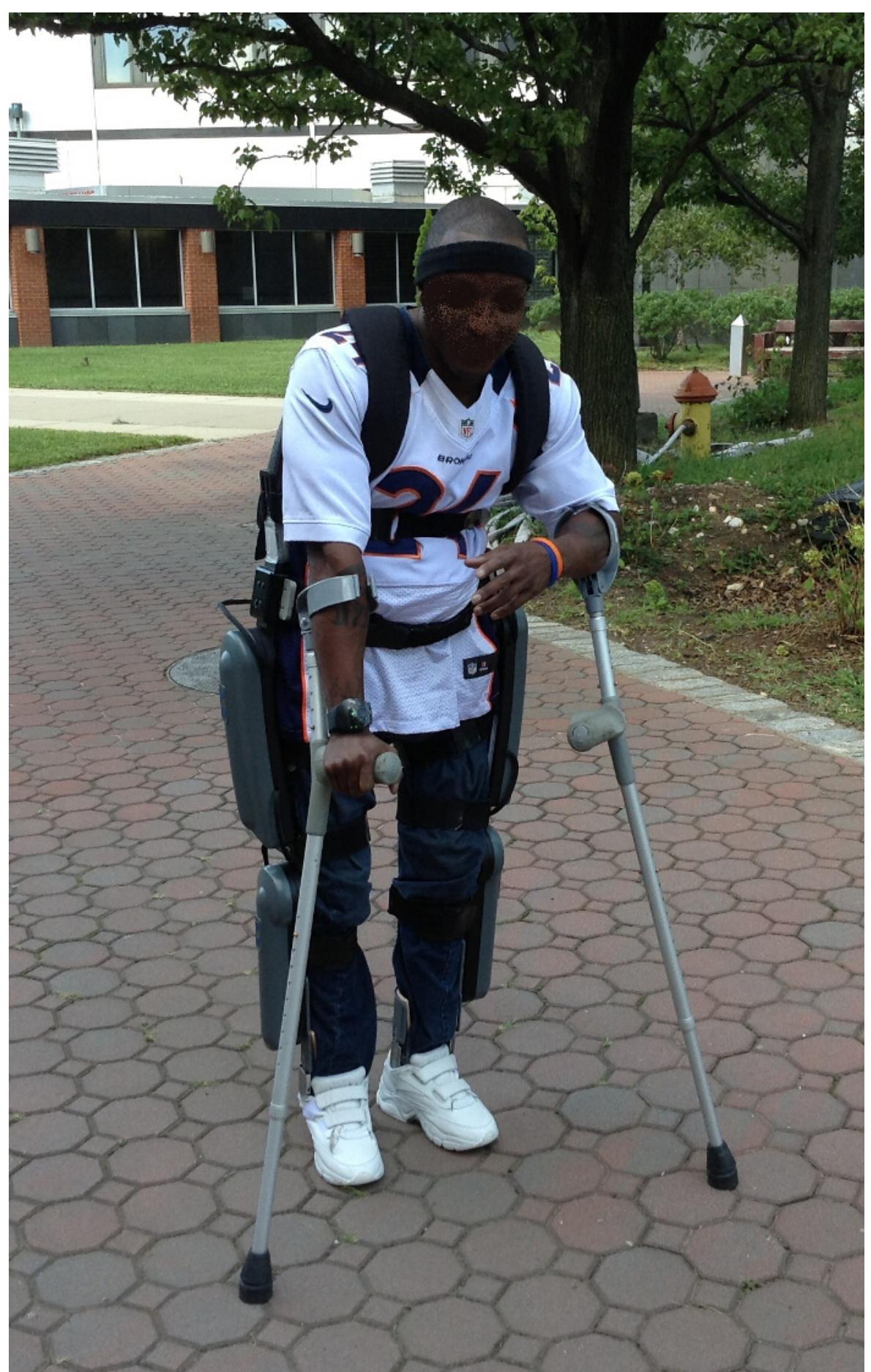

Figure 2. One handed crutch balance. This figure demonstrates a person standing still and balancing with only 1 crutch. Please click here to view a larger version of this figure. 


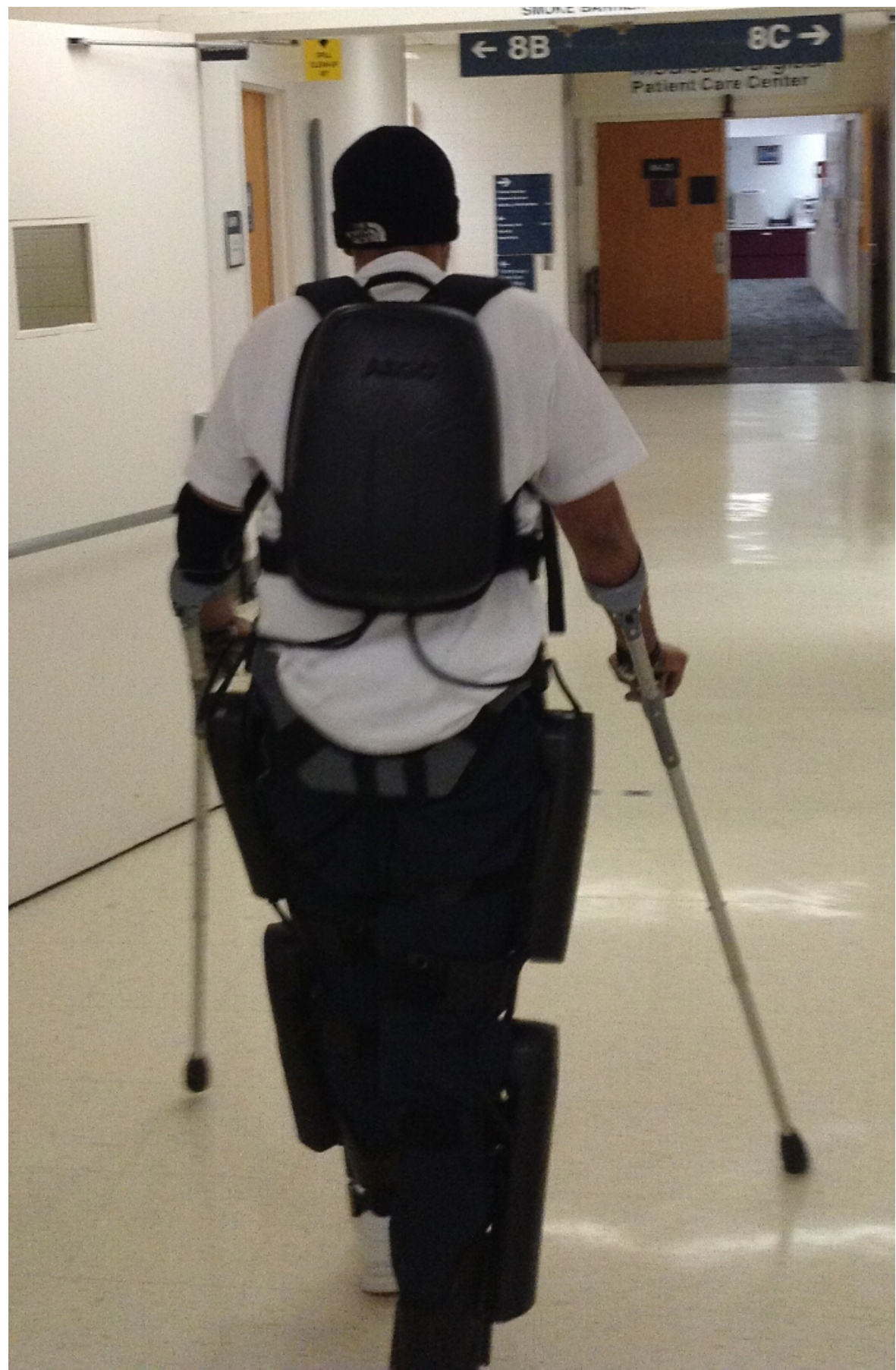

Figure 3. Walking indoors on a smooth surface. This figure demonstrates a person walking indoors on a flat surface. Please click here to view a larger version of this figure. 


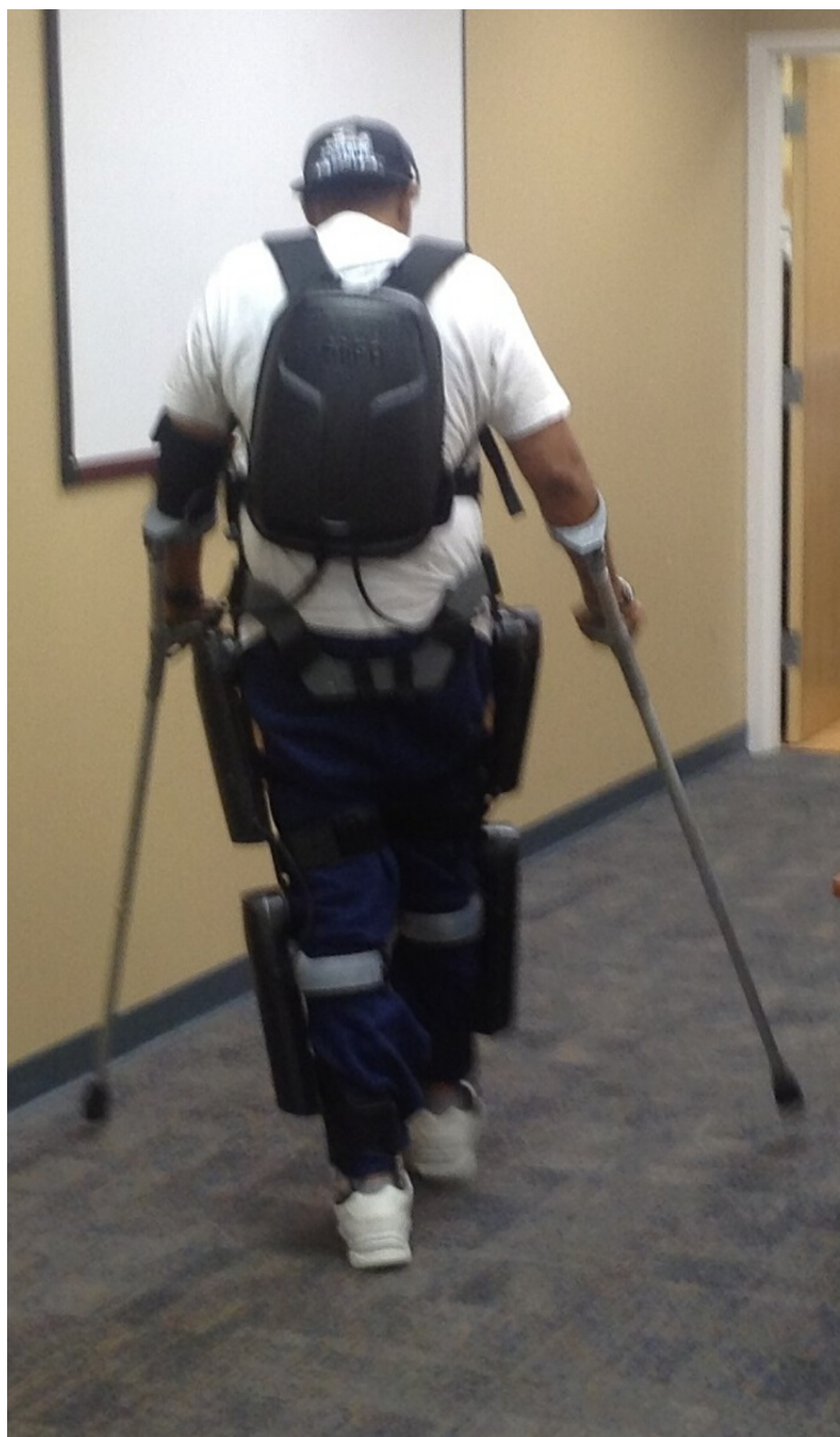

Figure 4. Walking on carpet. This figure demonstrates a person walking indoors on a carpeted surface. Please click here to view a larger version of this figure. 


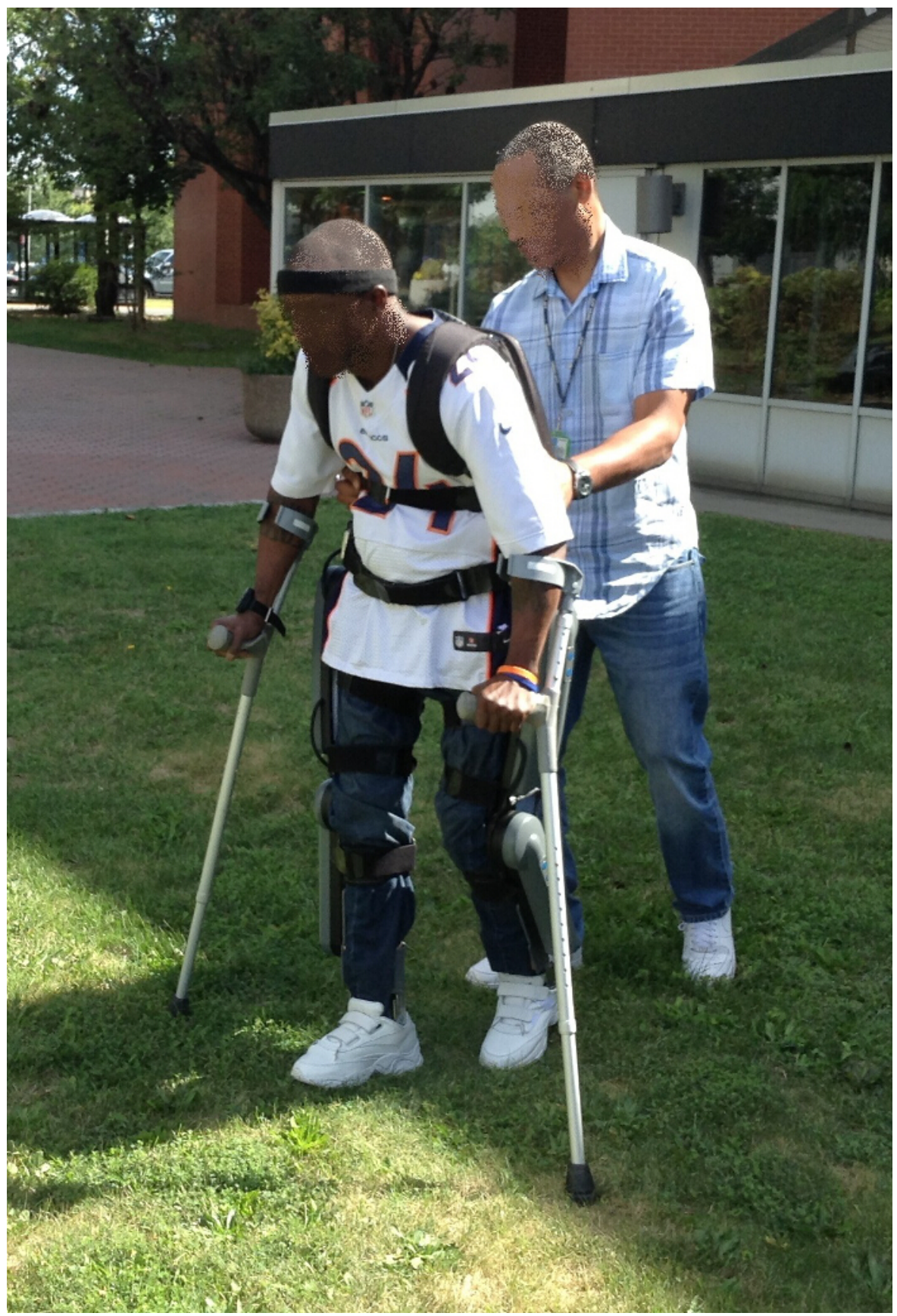

Figure 5. Walking outdoors on grass. This figure demonstrates a person walking outdoors on grass. Please click here to view a larger version of this figure. 


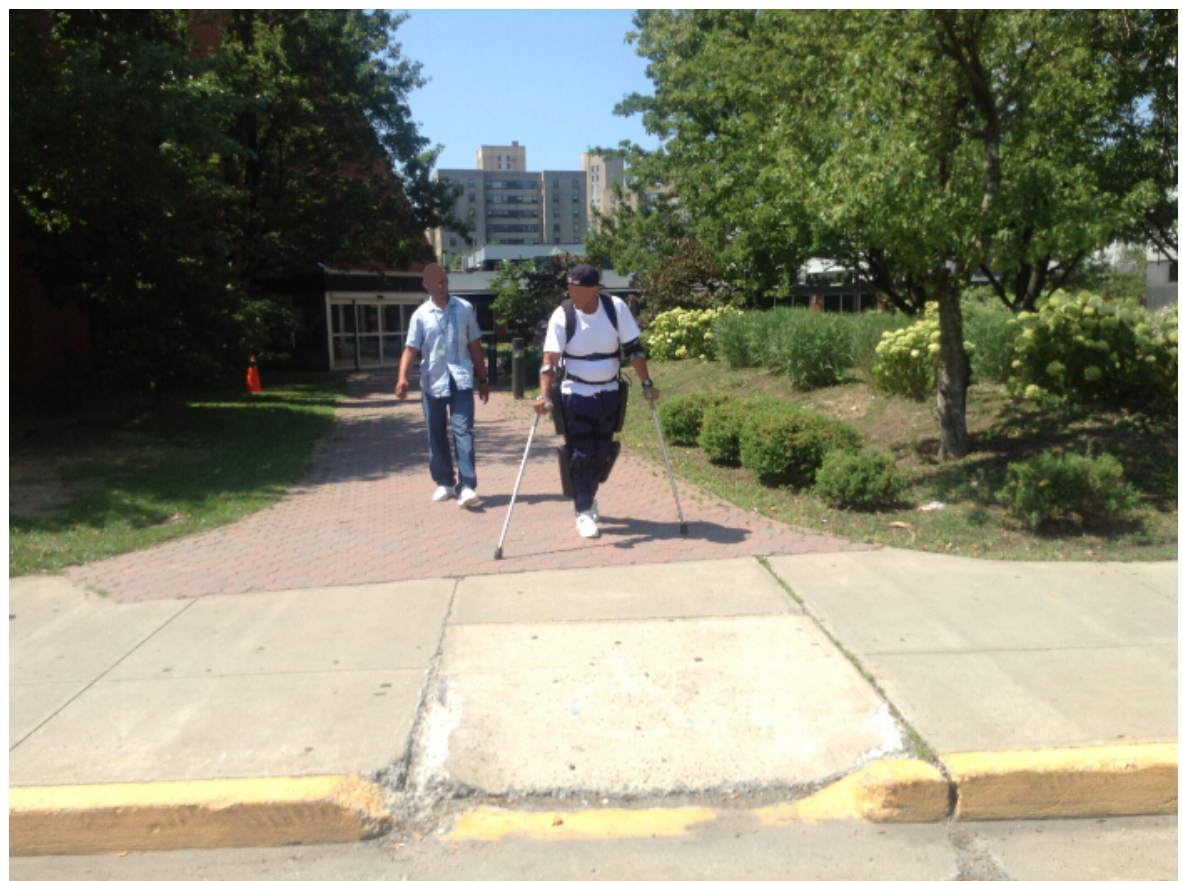

Figure 6. Walking on slopes. This figure demonstrates a person walking outdoors down a curb cutout. Please click here to view a larger version of this figure.

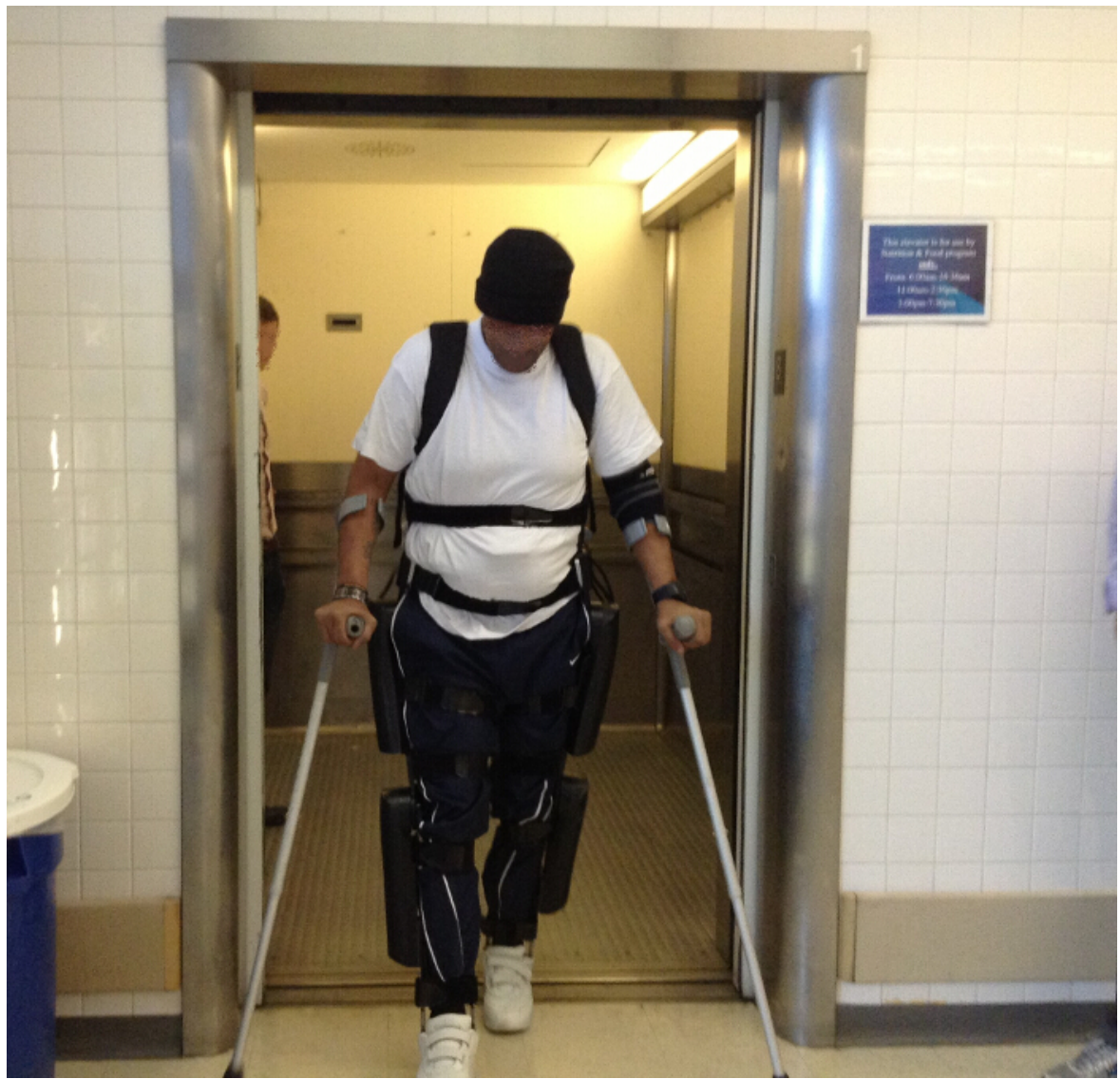

Figure 7. Navigating an elevator. This figure demonstrates a person walking out of a timed door setting such as an elevator door. Please click here to view a larger version of this figure. 


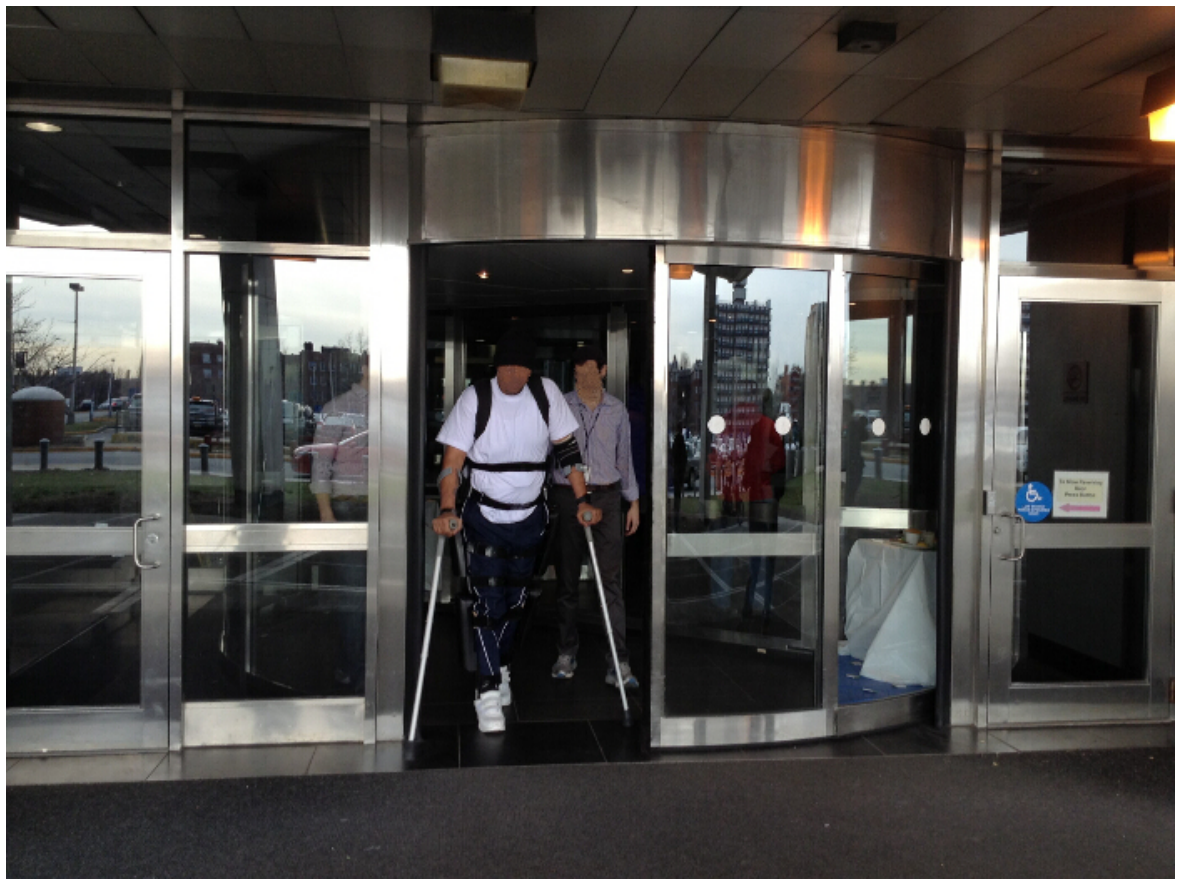

Figure 8. Walking out of a revolving door. This figure demonstrates a person walking out of a revolving door. Please click here to view a larger version of this figure.

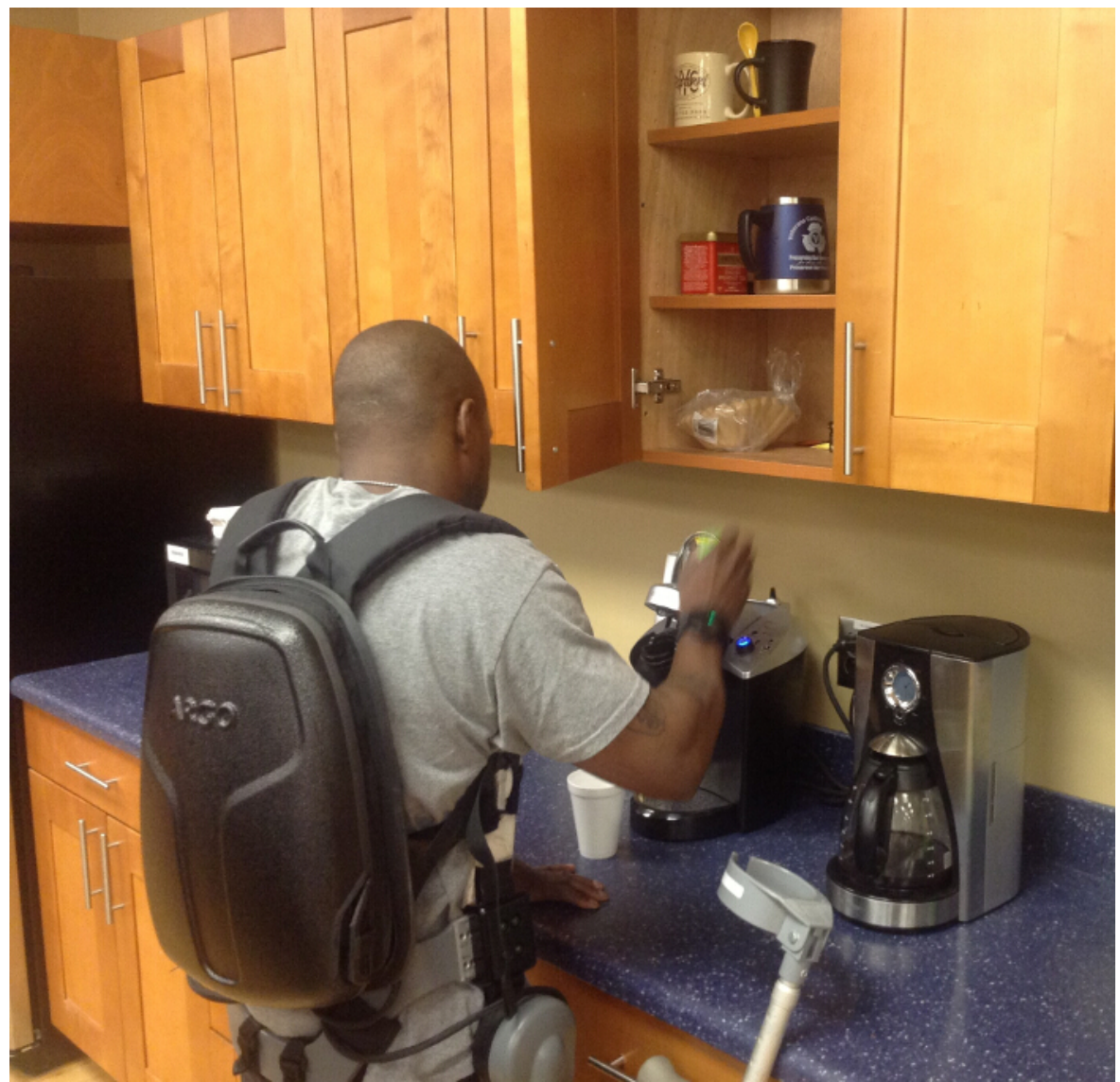

Figure 9. Overhead cabinet and countertop reaching. This figure demonstrates a person taking items out of an overhead cabinet. Please click here to view a larger version of this figure. 


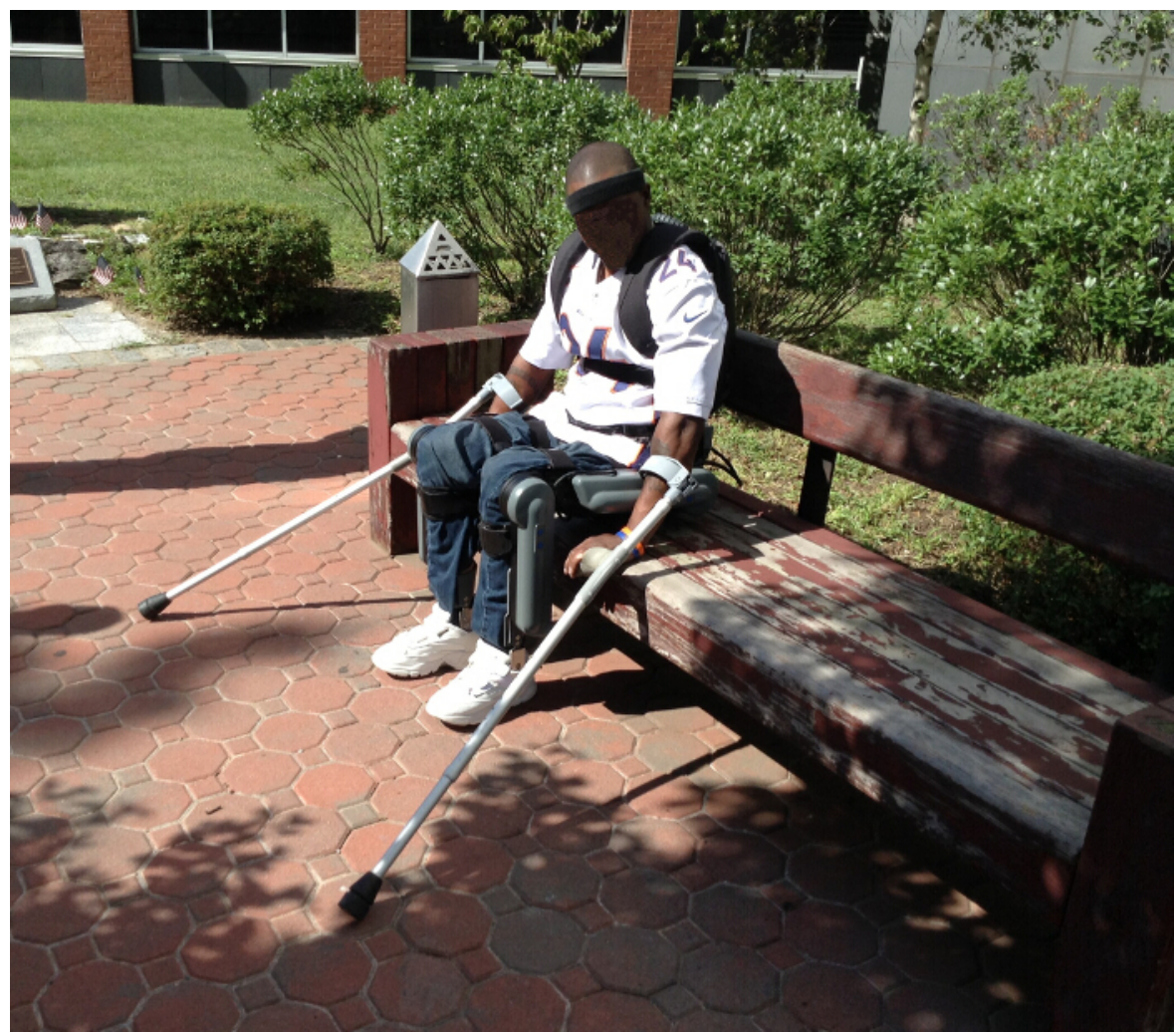

Figure 10. Sitting outside on a park bench. This figure demonstrates a person sitting outside on a park bench. Please click here to view a larger version of this figure.

\section{Average Speeds Over 10 Session Intervals}

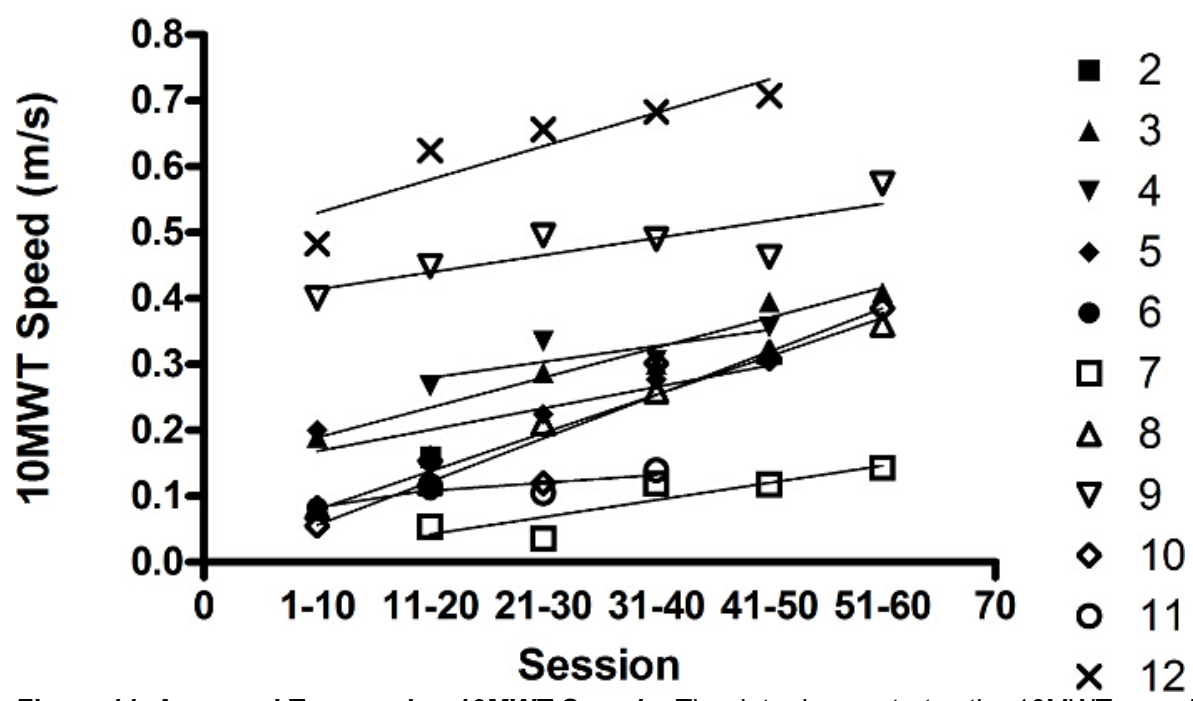

Figure 11. Averaged Ten-session 10MWT Speeds. The data demonstrates the 10MWT speeds for the first 60 sessions of training averaged by ten session intervals. The $x$-axis describes the sessions and the $y$-axis describes the average speed $(\mathrm{m} / \mathrm{sec})$ calculated from the $10 M W T$ result obtained during the participants training session. A linear best fit line was overlaid on each participant's results. Please click here to view a larger version of this figure. 


\begin{tabular}{|c|c|c|c|c|c|c|c|c|c|c|c|c|c|c|}
\hline \multicolumn{8}{|c|}{ Demographic Characteristics } & \multicolumn{7}{|c|}{ Walk Tests (WT) and Levels of Assistance (LOA) } \\
\hline \multirow[t]{2}{*}{ SID } & \multirow{2}{*}{$\begin{array}{l}\text { Age } \\
(y)\end{array}$} & \multirow{2}{*}{\begin{tabular}{|l}
$\mathrm{Ht}$ \\
$(\mathrm{cm})$
\end{tabular}} & \multirow{2}{*}{$\begin{array}{l}\mathrm{Wt} \\
(\mathrm{kg})\end{array}$} & \multirow[t]{2}{*}{ Gender } & \multirow{2}{*}{$\begin{array}{l}\text { DOI } \\
(y)\end{array}$} & \multirow[t]{2}{*}{ LOI } & \multirow[t]{2}{*}{ AIS } & \multicolumn{2}{|c|}{$10 \mathrm{~m} \mathrm{WT}$} & \multicolumn{2}{|c|}{ 6-min WT } & \multirow{2}{*}{\begin{tabular}{|l|} 
TUG \\
(sec)
\end{tabular}} & \multirow[t]{2}{*}{ (LOA) } & \multirow{2}{*}{$\begin{array}{l}\text { Assess } \\
\text { ment } \\
\text { Session }\end{array}$} \\
\hline & & & & & & & & $(\sec )$ & $(\mathrm{m} / \mathrm{sec})$ & $(\mathrm{m})$ & $(\mathrm{m} / \mathrm{sec})$ & & & \\
\hline 1 & 34 & 173 & 66.7 & Male & 9 & T4 & B & 39 & 0.26 & 90 & 0.25 & 83 & Min & 89 \\
\hline 2 & 48 & 168 & 68 & Male & 4 & T10 & A & 62 & 0.16 & 51 & 0.14 & NP & Min & 18 \\
\hline 3 & 44 & 183 & 77.1 & Male & 4.5 & T4 & $A$ & 20 & 0.50 & 209 & 0.58 & 56 & $\mathrm{MI}$ & 63 \\
\hline 4 & 58 & 160 & 64.4 & Female & 1.5 & C8/T8 & $\mathrm{A}(\mathrm{NT})$ & 24 & 0.42 & 139 & 0.39 & 59 & $\mathrm{MI}$ & 43 \\
\hline 5 & 61 & 175 & 72.6 & Male & 14 & T11 & $A$ & 23 & 0.44 & 137 & 0.38 & 66 & $\mathrm{MI}$ & 37 \\
\hline 6 & 24 & 185 & 74.8 & Male & 5 & T5 & A & 56 & 0.18 & 60 & 0.17 & NP & Min & 12 \\
\hline 7 & 40 & 183 & 88.5 & Male & 1.5 & T1 & $B$ & 61 & 0.16 & 51 & 0.14 & 70 & $S$ & 102 \\
\hline 8 & 56 & 175 & 83.9 & Male & 3 & T9 & $A$ & 22 & 0.46 & 151 & 0.42 & 116 & $S$ & 51 \\
\hline 9 & 50 & 183 & 99.8 & Male & 11 & T7 & $A$ & 17 & 0.59 & 208 & 0.58 & 56 & $\mathrm{Ml}$ & 56 \\
\hline 10 & 37 & 170 & 65.8 & Male & 6 & T2 & $A$ & 22 & 0.46 & 150 & 0.42 & 63 & Min & 59 \\
\hline 11 & 64 & 173 & 72.8 & Male & 3 & T2 & $A$ & 78 & 0.13 & 46 & 0.13 & NP & Mod & 28 \\
\hline 12 & 37 & 152 & 65.8 & Female & 19 & C8 & $\mathrm{C}(\mathrm{NT})$ & 14 & 0.71 & 256 & 0.71 & 42 & $\mathrm{Ml}$ & 39 \\
\hline
\end{tabular}

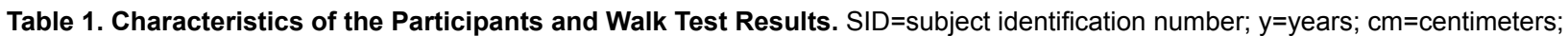
$\mathrm{kg}=$ ilograms; DOI=duration of injury; LOI=level of injury; AIS=American Spinal Injury Association Impairment Scale; LOA=level of assistance; $\mathrm{s}=$ seconds; $\mathrm{m}=$ meters; NP=Not-Performed and NT=non-traumatic SCl. LOA was adapted from the FIM as one of the following: moderate assistance (Mod) - participant performs $50 \%$ to $74 \%$ of the task; minimal assistance (Min) - the user performs $75 \%$ or more of the task; supervision (S) - the trainer is not touching the participant but is close enough to reach in to provide support for balance or guidance as needed; and modified independence (MI) - the trainer does not provide any assistance, and the participant is fully independent while walking in device. Re-print with permission, from Yang A, Asselin P, Knezevic S, Kornfeld S, Spungen A. Assessment of in-hospital walking velocity and level of assistance in a powered exoskeleton in persons with spinal cord injury. Top Spinal Cord Inj Rehabil. 2015; 21(2):100-109. Copyright (C) 2015 Thomas Land Publishers, Inc.

\section{Discussion}

During the past five years, our group has developed a successful screening and training program for participants to use the type of powered exoskeleton that requires crutches. We have trained individuals with motor complete paralysis as well as those with incomplete paralysis. This training program has the potential to be modified and built upon with additional devices that require the use of crutches, or newer versions of the existing devices.

Standardization of a training program is important to ensure participant safety, successful use of the device, identify staff resources, and to acquire consistent results. Key points in a good training program include appropriate candidate selection, proper fitting of the device, appropriate skill progression, and providing assistance on the shoulders or on an area with intact sensation to enable the user to recognize the required force and movement, promoting adaption of their movements during the subsequent stepping actions. It is important to practice this strategic dance between the trainer and the user in order to minimize trainer support, thus helping the user gain expertise and independence in the device. Trainers should avoid assisting below the participant's level of sensation since this action results in difficulty in becoming independent in the exoskeleton. Another key point to improve walking skill is to challenge the participant with walking on various surfaces and in different environments. Participants perceive walking indoors and on flat/smooth surfaces in the medical center to be easier than ambulating on a carpeted floor. Walking on carpeted floors, in turn, is reported to be easier than walking outdoors on uneven surfaces such as concrete or asphalt. Walking up and down different slope gradients force the participant to adapt their walking strategy because the method of weight shifting becomes more challenging due to the altered center of balance presented by the slope. All of these challenging environments are commonly encountered within the community and therefore, are very important to practice in a controlled setting to properly prepare the participant.

There have been several reports in persons with $\mathrm{SCI}$ who have learned to use a powered exoskeleton to safely ambulate overground ${ }^{16-19,21,36}$. Many of the participants in these reports had little to no residual function or sensation in their lower extremities. No serious adverse events were reported from these studies and the devices were deemed safe to use with the proper training. The adverse events reported included skin abrasions, bruising or redness of the skin, and fatigue of the upper extremities, especially during the initial training sessions ${ }^{16,19,36}$. It was noted that with continued training, participants noticed a reduction of upper extremity fatigue and skin abrasions resolved quickly with better fitting of the device. Future bruising and redness were avoided with adjustment of the straps and strategic placement of additional padding surrounding the affected area.

Proficiency in the use of the device is determined by the ability to achieve faster ambulation speeds, reduced levels of assistance, and safe ambulation in varied environments. Prior reports of walking ability showed that those who were more independent would ambulate faster than those who needed assistance. A report by van Hedel et al. categorized walkers as "assisted walkers" if they could ambulate with a minimum speed of $0.44 \pm 0.14 \mathrm{~m} / \mathrm{sec}$; a speed associated with those who chose to walk outdoors with assistance over using their wheelchair ${ }^{42}$. This walking speed is similar to the $0.40 \mathrm{~m} / \mathrm{sec}$ speed of the limited community ambulators reported in persons with stroke. ${ }^{43}$ Although only a few studies have reported ambulation speed and level of assistance using robotic exoskeletons, these studies indicated that many participants were able to achieve the $0.40 \mathrm{~m} / \mathrm{sec}$ walking speed mentioned in these previous reports. A report using a powered exoskeleton showed that 7 of 12 
participants were able to ambulate faster than $0.40 \mathrm{~m} / \mathrm{sec}^{18}$. Another investigation using a different powered exoskeleton was able to illustrate 6 of 16 participants successfully ambulating greater than $0.40 \mathrm{~m} / \mathrm{sec}^{36}$. Although reports using a third powered exoskeleton have not demonstrated walking speeds of $0.40 \mathrm{~m} / \mathrm{sec}^{22,44}$, future reports may show increased walking speeds with further training and/or adaptions in that device. Thus far, all studies using powered exoskeletons have reported those needing greater levels of assistance walked at slower speeds. One thought discussed in these reports was that although some of the participants did not ambulate above the $0.40 \mathrm{~m} / \mathrm{sec}$ speed, they were able to ambulate at the level of "supervision" as defined in the FIM scale. These reports suggest that, with additional training or modifications to the devices, ambulation at these faster speeds may be achieved.

Energy expenditure measured by oxygen consumption has been demonstrated to be increased with exoskeletal-assisted walking, but not above the threshold that is unduly fatiguing. Eight participants who ambulated in the powered exoskeleton at an average pace of $0.22 \pm 0.11 \mathrm{~m} / \mathrm{sec}$ demonstrated walking oxygen consumption rates of $11.2 \pm 1.7 \mathrm{ml} / \mathrm{kg} / \mathrm{min}$ and heart rates of $118 \pm 21 \mathrm{bmp}(48 \% \pm 16 \%$ heart rate reserve), both of which were a significant increase from sitting and standing ${ }^{17}$, but significantly below the maximum predicted values. Another report using a different powered exoskeleton, evaluated oxygen consumption in 5 participants during 2 bouts of walking and reported $9.5 \pm 0.8 \mathrm{ml} / \mathrm{kg} / \mathrm{min} \mathrm{when}$ walking at $0.19 \pm 0.01 \mathrm{~m} / \mathrm{sec}$ and $11.5 \pm 1.4 \mathrm{ml} / \mathrm{kg} / \mathrm{min}$ when walking at $0.27 \pm 0.05 \mathrm{~m} / \mathrm{sec}^{21}$. Both of these studies demonstrated that participants ambulating at a moderate intensity were above the minimal training intensity threshold determined by the American College of Sports Medicine to be effective for cardiorespiratory benefits ${ }^{45}$. This suggests that these devices have the potential to be used for longer periods of time, providing a form of activity that if performed regularly may be expected to lead to improvements in the user's fitness, body composition and lipid profile.

The powered exoskeletons offer a form of modified independence (level six as defined by the FIM) for standing and overground ambulation for persons with upper extremity function. Future devices may be designed to ambulate at faster speeds or provide a greater ability to vary the desired ambulation speed. Future exoskeletons may also be designed for those with limited hand and arm function (such as those with tetraplegia) by maintaining the user's balance with additional trunk support and providing another mechanism than holding a crutch for maintaining balance. Advancements in brain control may one day be available to be incorporated to control the walking movement ${ }^{20}$. Within this emerging field, the basic training concepts presented may be applicable to the current and future powered exoskeletons, but should be tailored to the user and the exoskeleton being used.

Standardized training strategies are currently utilized for successful participant exoskeletal-assisted walking; future modifications of these devices may need adaptions to the training paradigm. Teaching qualified SCI health-care professionals to appropriately train persons with SCI to perform exoskeletal-assisted walking is needed for the continued use and prescription of these devices. The future is bright for these devices; the use of powered exoskeletons by persons with $\mathrm{SCl}$ would become more widespread with the establishment of training programs in medical and rehabilitation centers throughout the world. Additionally, future research may show that regular exoskeletal-assisted walking improves many of the secondary medical complications that are associated with immobility and paralysis from spinal cord injury.

\section{Disclosures}

The authors have nothing to disclose.

\section{Acknowledgements}

Support for this work was obtained by the VA Rehabilitation Research \& Development National Center of Excellence for the Medical Consequences of Spinal Cord Injury (VA RR\&D \#B9212C). Two of the four powered exoskeleton devices were used on a loaner basis at no cost from ReWalk Robotics, Inc. (Marlborough, Massachusetts). Additionally a portion of participants obtained Orthopedic shoes which were donated by Aetrex Worldwide Inc. (Teaneck, New Jersey).

Assistance from Denis Doyle-Green was invaluable during the training program and we thank him for this. We would also like to thank the physical therapists from the Rehabilitation and Spinal Cord Injury Services at the James J. Peters VA Medical Center for their advisement and consultations.

1. Kamenetz, H. L. A brief history of the wheelchair. Journal of the history of medicine and allied sciences. 24, 205-210 (1969).

2. Nene, A., \& Patrick, J. Energy cost of paraplegic locomotion with the ORLAU ParaWalker. Spinal Cord. 27, 5-18 (1989).

3. Massucci, M., Brunetti, G., Piperno, R., Betti, L., \& Franceschini, M. Walking with the advanced reciprocating gait orthosis (ARGO) in thoracic paraplegic patients: energy expenditure and cardiorespiratory performance. Spinal Cord. 36, 223-227 (1998).

4. ljzerman, M. et al. The influence of the reciprocal cable linkage in the advanced reciprocating gait orthosis on paraplegic gait performance. Prosthetics and Orthotics International. 21, 52-61 (1997).

5. Kawashima, N., Taguchi, D., Nakazawa, K., \& Akai, M. Effect of lesion level on the orthotic gait performance in individuals with complete paraplegia. Spinal Cord. 44, 487-494 (2006).

6. Solomonow, M. et al. The RGO Generation II: muscle stimulation powered orthosis as a practical walking system for thoracic paraplegics. Orthopedics. 12, 1309-1315 (1989).

7. Nene, A., Hermens, H., \& Zilvold, G. Paraplegic locomotion: a review. Spinal Cord. 34, 507-524 (1996).

8. Durfee, W. K., \& Rivard, A. Preliminary Design and Simulation of a Pneumatic, Stored-Energy, Hybrid Orthosis for Gait Restoration in ASME 2004 International Mechanical Engineering Congress and Exposition. 235-241 (American Society of Mechanical Engineers) (2004).

9. Goldfarb, M., Korkowski, K., Harrold, B., \& Durfee, W. Preliminary evaluation of a controlled-brake orthosis for FES-aided gait. Neural Systems and Rehabilitation Engineering, IEEE Transactions on. 11, 241-248 (2003).

10. Hughes, J. Powered lower limb orthotics in paraplegia. Paraplegia. 9, 191 (1972).

11. Nene, A., \& Patrick, J. Energy cost of paraplegic locomotion using the ParaWalker--electrical stimulation" hybrid" orthosis. Arch Phys Med Rehabil. 71, 116 (1990). 
12. McClelland, M., Andrews, B., Patrick, J., \& El Masri, W. Augmentation of the Oswestry Parawalker orthosis by means of surface electrical stimulation: gait analysis of three patients. Spinal Cord. 25, 32-38 (1987).

13. Vukobratovic, M., Hristic, D., \& Stojiljkovic, Z. Development of active anthropomorphic exoskeletons. Medical and Biological Engineering and Computing. 12, 66-80 (1974).

14. Stein, J., Bishop, L., Stein, D. J., \& Wong, C. K. Gait Training with a Robotic Leg Brace After Stroke: A Randomized Controlled Pilot Study. American Journal of Physical Medicine \& Rehabilitation. 93, 987-994 (2014).

15. Bortole, M. et al. The $\mathrm{H} 2$ robotic exoskeleton for gait rehabilitation after stroke: early findings from a clinical study. Journal of neuroengineering and rehabilitation. 12, 54 (2015).

16. Zeilig, G. et al. Safety and tolerance of the ReWalk exoskeleton suit for ambulation by people with complete spinal cord injury: A pilot study. Journal of Spinal Cord Medicine. 35, 96-101 (2012).

17. Asselin, P. et al. Heart rate and oxygen demand of powered exoskeleton-assisted walking in persons with paraplegia. JRRD. 52, 147-158 (2015).

18. Yang, A., Asselin, P., Knezevic, S., Kornfeld, S., \& Spungen, A. Assessment of In-Hospital Walking Velocity and Level of Assistance in a Powered Exoskeleton in Persons with Spinal Cord Injury. Topics in Spinal Cord Injury Rehabilitation. 21, 100-109 (2015).

19. Kolakowsky-Hayner, S. A., Crew, J., Moran, S., \& Shah, A. Safety and feasibility of using the Ekso ${ }^{\mathrm{TM}}$ bionic exoskeleton to aid ambulation after spinal cord injury. J Spine. S4 (2013).

20. Kilicarslan, A., Prasad, S., Grossman, R. G., \& Contreras-Vidal, J. L. High accuracy decoding of user intentions using EEG to control a lowerbody exoskeleton in Engineering in medicine and biology society (EMBC), 2013 35th annual international conference of the IEEE. 5606-5609 (IEEE) (2013).

21. Evans, N., Hartigan, C., Kandilakis, C., Pharo, E., \& Clesson, I. Acute Cardiorespiratory and Metabolic Responses During ExoskeletonAssisted Walking Overground Among Persons with Chronic Spinal Cord Injury. Topics in Spinal Cord Injury Rehabilitation. 21, 122-132 (2015).

22. Kozlowski, A., Bryce, T., \& Dijkers, M. Time and Effort Required by Persons with Spinal Cord Injury to Learn to Use a Powered Exoskeleton for Assisted Walking. Topics in Spinal Cord Injury Rehabilitation. 21, 110-121 (2015).

23. Farris, R. J. et al. A preliminary assessment of legged mobility provided by a lower limb exoskeleton for persons with paraplegia. Neural Systems and Rehabilitation Engineering, IEEE Transactions on. 22, 482-490 (2014).

24. Farris, R. J., Quintero, H. A., \& Goldfarb, M. Performance evaluation of a lower limb exoskeleton for stair ascent and descent with Paraplegia in Engineering in Medicine and Biology Society (EMBC), 2012 Annual International Conference of the IEEE. 1908-1911 (IEEE) (2012).

25. Aach, M. et al. Voluntary driven exoskeleton as a new tool for rehabilitation in chronic spinal cord injury: a pilot study. The spine journal : official journal of the North American Spine Society. 14, 2847-2853 (2014).

26. Kubota, S. et al. Feasibility of rehabilitation training with a newly developed wearable robot for patients with limited mobility. Arch Phys Med Rehabil. 94, 1080-1087 (2013).

27. Wall, A., Borg, J., \& Palmcrantz, S. Clinical application of the Hybrid Assistive Limb (HAL) for gait training-a systematic review. Frontiers in systems neuroscience. 9 (2015).

28. Bauman, W. et al. Effect of Pamidronate Administration on Bone in Patients with Acute Spinal Cord Injury. J Rehabil Res Dev. 42, 305-313 (2005).

29. Bauman, W. A. et al. Zoledronic acid administration failed to prevent bone loss at the knee in persons with acute spinal cord injury: an observational cohort study. Journal of bone and mineral metabolism. 1-12 (2014).

30. Bauman, W., Spungen, A., Wang, J., Pierson Jr, R., \& Schwartz, E. Continuous Loss of Bone During Chronic Immobilization: A Monozygotic Twin Study. Osteoporos Int. 10, 123-127 (1999).

31. Garland, D., Adkins, R., \& Stewart, C. Fracture threshold and risk for osteoporosis and pathologic fractures in individuals with spinal cord injury. Topics in Spinal Cord Injury Rehabilitation. 11, 61-69 (2005).

32. Eser, P., Frotzler, A., Zehnder, Y., \& Denoth, J. Fracture threshold in the femur and tibia of people with spinal cord injury as determined by peripheral quantitative computed tomography. Arch Phys Med Rehabil. 86, 498-504 (2005).

33. Lazo, M. et al. Osteoporosis and risk of fracture in men with spinal cord injury. Spinal cord. 39, 208-214 (2001).

34. Yarkony, G. M., Bass, L. M., Keenan, V., \& Meyer, P. R. Contractures complicating spinal cord injury: incidence and comparison between spinal cord centre and general hospital acute care. Spinal Cord. 23, 265-271 (1985).

35. Richardson, R. R., \& Meyer, P. R. Prevalence and incidence of pressure sores in acute spinal cord injuries. Spinal Cord. 19, 235-247 (1981).

36. Hartigan, C. et al. Mobility Outcomes Following Five Training Sessions with a Powered Exoskeleton. Topics in Spinal Cord Injury Rehabilitation. 21, 93-99 (2015).

37. Maynard, F. M. et al. International standards for neurological and functional classification of spinal cord injury. Spinal cord. 35, 266-274 (1997).

38. Granger, C. V., Hamilton, B. B., Linacre, J. M., Heinemann, A. W., \& Wright, B. D. Performance profiles of the functional independence measure. American Journal of Physical Medicine \& Rehabilitation. 72, 84-89 (1993).

39. Guyatt, G. H. et al. The 6-minute walk: a new measure of exercise capacity in patients with chronic heart failure. Canadian Medical Association Journal. 132, 919 (1985).

40. van Hedel, H. J., Wirz, M., \& Dietz, V. Assessing walking ability in subjects with spinal cord injury: validity and reliability of 3 walking tests. Arch Phys Med Rehabil. 86, 190-196 (2005).

41. Podsiadlo, D., \& Richardson, S. The timed "Up \& Go": a test of basic functional mobility for frail elderly persons. Journal of the American geriatrics Society. 39, 142-148 (1991).

42. van Hedel, H. J. Gait speed in relation to categories of functional ambulation after spinal cord injury. Neurorehabilitation and neural repair. 23, 343-350 (2009).

43. Perry, J., Garrett, M., Gronley, J. K., \& Mulroy, S. J. Classification of walking handicap in the stroke population. Stroke. 26, 982-989 (1995)

44. Kressler, J. et al. Understanding therapeutic benefits of overground bionic ambulation: exploratory case series in persons with chronic, complete spinal cord injury. Arch Phys Med Rehabil. 95, 1878-1887. e1874 (2014).

45. Pollock, M. L. et al. ACSM position stand: the recommended quantity and quality of exercise for developing and maintaining cardiorespiratory and muscular fitness, and flexibility in healthy adults. Med Sci Sports Exerc. 30, 975-991 (1998). 